Letters to the Editor
I do not know if I am alone in noticing this problem but I would be grateful if through your columns we might instigate a debate as to how this policy might be taken forward.

\section{T. BEATTIE}

Consultant, Royal Hospital for Sick Children, Sciennes Road, Edinburgh

\section{Training in major incident planning}

I was very interested to read the article by Brennan et al. ${ }^{1}$ I share their concerns that few doctors receive training in major incident management. Very few doctors will ever be asked to be medical incident officers by an ambulance service, but substantially more will be asked either to be part of a team sent to a major incident, or indeed a hospital medical team sent to any incident.

For the last year I have been teaching house and senior house staff of all specialties at this Hospital how to be part of a major incident team. The lecture is designed to dovetail with the plans of the London Ambulance Service, and to familiarize doctors with the command and control structures of the three main emergency services as well as to outline what is expected of the individual doctor.

As far as I am aware this is the only teaching aimed specifically at members of a mobile medical team. The lecture has proved very popular with junior staff, and I would support Dr Brennan's call for improving training of staff in major incident support.

\section{REFERENCE}

Brennan L.,Sage F.J. \& Simpson A. (1994) Major Incident planning in South East Thames Region: a survey of medical staff awareness and training. Journal of Accident and Emergency Medicine 11, 85-89.

\section{R. COTTINGHAM}

Senior Registrar, Accident and Emergency Department, Royal Free Hospital, Pond Street, London

\section{Contamination of clothing in accident and emergency departments}

I would agree with Mr Steedman that the contamination of skin and clothing of staff working in accident and emergency (A\&E) departments is both only confined to major inner-city departments, as illustrated by the findings of survey where medical and nursing staff in the A\&E department at the Royal Alexandra Hospital Paisley, a district general hospital, reported 51 splashes in a 4-week survey period during which 4692 patients were treated.

Staff most frequently splashed were A\&E nurses with $51 \%$ of reported incidents (26 splashes), followed by $A \& E$ doctors at $35 \%$ ( 18 splashes). The remaining $14 \%$ (7) were to medical and surgical receiving staff. A total of $76.5 \%$ of splashes (39) involved blood. Although $2.6 \%$ of patients (124) were seen in the resuscitation room, $21.5 \%$ of splashes (11) occurred here. Suturing and wound management proved to be the most common cause of contamination accounting for $41 \%$ of splashes (21), which involved the trunk area in $51 \%$ (11). The practice of inserting an intra-venous cannula and withdrawing blood samples through the cannula accounted for a further $39 \%$ (20) of splashes and, of these, ungloved hands were splashed in $85 \%$ (17 incidents).

Both nurses and doctors working in A\&E departments should wear protective clothing and the importance of universal precautions needs to be emphasized firmly. Many splashes could be prevented if gloves and plastic aprons were worn whilst assessing wounded patients, suturing and in the resuscitation room. Gloves should always be worn during intra-venous cannula insertion and blood sampling.

\section{REFERENCE}

1. Steedman D.J. (1994) Protective clothing for accident and emergency personnel. Journal of Accident and Emergency Medicine 11, 17-19.

\section{A.J. IRELAND}

Senior Registrar, Accident and Emergency Department, Glasgow Royal Infirmary, Glasgow

\section{Head injuries in the accident and emergency department}

I read the article by Dr S.A. Wallace et al. with great interest. ${ }^{1}$ I agree that criteria for adults when ordering skull radiographs following head injury should be modified for paediatric patients.

I would like to bring to the attention of readers recently published guidelines for skull radiographs in paediatric patients with head injury. ${ }^{2}$ These are an intrinsic part of the Advanced Paediatric Life 